\title{
Acontecimientos de lectura: experiencia política y compromiso ético'
}

\section{Reading Events: Political Experience and Ethical Commitment}

\author{
ALDO OCAMPO GONZÁLEZ \\ Centro de Estudios Latinoamericanos de Educación Inclusiva (CELEI) \\ Chile \\ CONCEPCIÓN LÓPEZ-ANDRADA
}

Centro de Estudios Latinoamericanos de Educación Inclusiva (CELEI).

\author{
España \\ aldo.ocampo.gonzalez@gmail.com \\ clopezc@unex.es
}

(Recibido: 22-O2-2OI9; aceptado: I6-O7-2019)

Resumen. Este trabajo tiene como propósito el análisis del derecho a la lectura y a la educación como una práctica cultural y política desde perspectivas discrepantes a las formas de universalismo históricamente validadas por el imperialismo cultural que configuran las políticas del libro y las políticas educativas en una expresión homogeneizadora. De tal manera que resulta posible afirmar que los derechos sociales y culturales se articulan desde una perspectiva monológica y monolítica. En el transcurso de este ensayo se aborda el pensamiento fronterizo como resistencia a estas prácticas monotópicas que sustentan la actividad de la ciudadanía lectora y cultural, erradicando las relaciones de superioridad frente a otras expresiones y modalidades de intervención. La lectura crea un lenguaje crítico común que permite subvertir los variados dispositivos de opresión y dominación. Así, la frontería emerge como espacio de producción y re-articulación del conocimiento. La lectura en el contexto de la Educación Inclusiva se convierte en un acto performativo que constituye un espacio significativo para el cambio, la invención y la creación de otros mundos y modalidades de educación. Es ante todo un acontecimiento -lugar de imaginación de futuros posibles-, y una respuesta de creación a lo posible.

Palabras clave: lectura; ciudadanía; educación inclusiva; alfabetización; acontecimiento.
Abstract. The purpose of this work is to analyze the right to reading and to education as a cultural and political practice, from different perspectives of universalism historically validated by the cultural imperialism that makes book policies and educational policies a homogenizing expression. In such a way it is possible to affirm that social and cultural rights are articulated from a monological and monolithic perspective. In the course of this essay, border thinking is approached as resistance to these monotopic practices that sustain the activity of reading and cultural citizenship, eradicating relations of superiority vis-à-vis other expressions and modalities of intervention. Reading creates a common critical language that allows for subverting the various devices of oppression and domination. Thus, the frontier emerges as a space of production and re-articulation of knowledge. Reading in the context of Inclusive Education becomes a performative act and constitutes a significant space for change, invention, leisure and the creation of other worlds and modes of education. It is first and foremost an event -place of imagination of possible futures-, it is a response of creation to the possible.

Keywords: reading; citizenship; inclusive education; literacy; event.

\footnotetext{
I Para citar este artículo: Ocampo González, Aldo y López-Andrada, Concepción (2020). Acontecimientos de lectura: experiencia política y compromiso ético. Alabe 21. [www.revistaalabe.com]

DOI: I0.I5645/Alabe2O2O.2I.9
} 


\section{Introducción: pensamiento fronterizo y justicia a través del derecho a la lectura}

Con la publicación del libro Bordelands/La Frontera: the new mestiza en I987, Gloria Anzaldúa incorpora el concepto de "pensamiento fronterizo". Esta noción con relación al ámbito de estudio de las prácticas lectoras concibe su quehacer emancipatorio en una zona indeterminada y redefine su compromiso ético y político a partir de los ejes de configuración de las prácticas de subalternidad (Spivak, 20o8; Mohanty, 2008; Shohat, 2008). Las prácticas lectoras a través del lente de los Estudios Postcoloniales (Spivak, 2008; Mohanty, 2008, Mezzadra, 2008) constituyen una invitación para pensar al límite, a la fabricación de una crítica interna a los marcos críticos hegemónicos de la alfabetización y de la lectura social, y en particular, es una formulación de cuestiones estratégicas para examinar las tensiones subalternas a través del ejercicio del derecho a la lectura. Emerge como un proyecto de deconstrucción -labor negativa- y edificación -labor positiva- de prácticas lectoras articuladas desde el centro crítico de relaciones exteriores. Epistemológicamente, la Educación Inclusiva es un campo que se construye dialécticamente entre las fuerzas de coacción de la labor negativa y positiva, consolida su actividad en rearticulación, entrelazamiento y engendramiento de diversos discursos, métodos, objetos, marcos teóricos, proyectos políticos y compromisos éticos. Es un campo ensamblado por complejas e intensas influencias y posicionalidades. Construye un nuevo estilo de subjetividad, forjando un acto performativo que constituye un espacio relevante para el cambio, la invención y la creación de otros mundos y modalidades de educación. Es ante todo un acontecimiento -lugar de imaginación de futuros posibles-, siendo una respuesta de creación a lo posible.

La lectura desde una perspectiva de subalternidad y diferencia examina la producción de los sujetos a través de una articulación predominantemente discursiva que se centra en un modo de apropiación, codificación y decodificación monolítica del conocimiento sobre el sujeto educativo y cultural. Su carácter monolítico y restrictivo se expresa en categorías analíticas legadas por influencias e intereses del individualismo metodológico en el que la condición de subalternidad o de diferencia se remite exclusivamente a una zona de abyección, diferenciación política y devaluación cultural ${ }^{2}$. Una praxis crítica y anti-opresiva en materia de derecho a la lectura consistirá en demostrar los modos en que determinados colectivos resisten y trabajan ante la expansión regenerativa del imperialismo cultural y del capitalismo cognitivo3.

¿Cuál es la relevancia política de las nociones de opresión, dominación, ideologías, inclusión, justicia y equidad al interior del marco analítico del derecho a la lectura? Cada uno de estos conceptos denota una variedad de fenómenos que desde una perspectiva analítica designan mecanismos de freno al autodesarrollo, y que supone un análisis

\footnotetext{
${ }^{2}$ Problema ontológico de los grupos sociales. Se agrega la ausencia de condiciones de reconocimiento y redistribución.

3 Sistema de regulación de la subjetividad.
} 
prácticamente invariable acerca de las desigualdades estructurales, una suspensión sobre sus múltiples formas de funcionamiento en la estructura social, cultural y educacional. Es necesario forjar principios analíticos que en el contexto de las prácticas de alfabetización promuevan:

[...] una práctica directamente política y discursiva en la medida en que tiene un sentido y es ideológica. La mejor manera de verla es como un modo de intervención en discursos hegemónicos particulares (por ejemplo, en la antropología, la sociología y la crítica literaria tradicionales); es una praxis política que rebate y resiste al imperativo totalizador del antiquísimo conjunto de conocimientos «legítimos» $\mathrm{y}$ «científicos»" (Mohanty, 2008: 7I).

La zona fronteriza como espacio de interminación permite la producción de nuevas categorías coherentes con el lenguaje de la multiplicidad, gramática sustentada en relaciones de exterioridad política y epistemológica. Recurriendo al principio de negatividad (Hegel, I969; Benjamin, 2008 y 2009; Adorno, I98I) reconoce las paradojas que sustentan la estructura ideológica de las prácticas culturales orientadas a la transformación del mundo, atiende a los diversos ejes de opresión múltiple que pueden emerger en determinas prácticas de alfabetización.

Los lectores en el marco de la visión acrítica de Educación Inclusiva se convierten en Otro ${ }^{4}$ ideológico y culturalmente construido según Mohanty (2008) a partir de discursos figurativos que omiten la materialidad del sujeto, su historia, su consciencia y su ubicación en el mundo. Coincidiendo con Giroux (I997), estas, sin duda alguna, son acciones que son acciones que la praxis lectora propone erradicar como parte del centro crítico como parte del centro crítico de la multiplicidad. Según Mohanty (2008), este modo de concebir a los lectores va más allá de un reconocimiento ingenuo y simplista del otro, más bien, "se trata de una relación arbitraria establecida por culturas particulares" (Mohanty, 2008: 72). Insiste la teórica añadiendo que, es "una imagen que parece construida de manera arbitraria pero que porta consigo, a pesar de ello, el sello de autoridad del discurso humanista occidental"(Mohanty, 2008: 72).

El estudio del derecho a la lectura articula su actividad a partir de una multiplicidad de posicionalidades emergiendo de las intersecciones de cada una de sus disciplinas, discursos, marcos teóricos, influencias, métodos, compromisos éticos y proyectos políticos que configuran su campo de producción. Al igual que campo epistemológico de la Educación Inclusiva, el estudio del derecho a la lectura consolida una red de relaciones intensas e inestables ${ }^{5}$, cuya organicidad tiene lugar en el pensamiento de la relación y del

\footnotetext{
${ }^{4}$ En el lenguaje de la alteridad, el Otro es significado con mayúsculas.

5 Una de las preocupaciones analíticas del dispositivo es que enfatiza en la naturaleza del vínculo. En el caso particular de la Educación Inclusiva, el dispositivo configura una red de movimientos de diversa naturaleza y magnitud, integrado por dislocaciones, alteraciones de funciones -rearticulación-, cambios de posiciones, capturas y forclusiones, etc. Sus vínculos expresan grados de varianza de diversa magnitud y formas de condicionamiento mutuo a través de cada elemento que en él confluye. La red forja un orden de producción específico que en el caso de la Educación Inclusiva opera a través de la metáfora de diáspora y de la diseminación
} 
encuentro de diversas singularidades epistemológicas. ¿A qué pragmática de la multiplicidad $^{6}$ nos conduce la Educación Inclusiva ${ }^{7}$ y las prácticas culturales? En este artículo se indaga en los usos universalizadores del derecho a la lectura y las desviaciones que establece su relación con el campo emergente y la aceptación institucional de la noción de Educación Inclusiva.

En los Estudios Postcoloniales según Shohat (2008) la lectura se convierte en una práctica cultural de resistencia y en una geopolítica del intercambio cultural; vista así, centra su atención en la dimensión "geográfica, histórica e institucionalmente, planteando al mismo tiempo dudas sobre su capacidad de acción política" (Shohat, 2008: IO4). Coincidimos, asimismo, con Benhabib (2008) en la necesidad de deconstruir -labor negativa- el concepto de universalismo y con ello, plantear otros universalismos que transciendan su acción esencializadora. La búsqueda de nuevas formas de universalismo se convierte en estrategias de redefinición de las ciudadanías, concebidas especialmente como un proyecto crítico-complejo. La acción universalista a juicio de Grosfoguel (2007) niega al sujeto y a sus modalidades enunciativas y omite la comprensión de las modalidades de funcionamiento del poder que permean la experiencia educativa y cultural. En este marco, el derecho a la lectura se convierte en un 'hybris de punto cero'propiedad de la lógica articulatoria del eurocentrismo, cristaliza un sistema ego-político en el que las prácticas de fomento a la lectura y, especialmente, la formación del profesorado se sustentan en un conjunto de sistemas de violencias epistemológicas.

Este trabajo tiene como propósito resituar en un espacio de tensión las prácticas lectoras en tanto resultado de diseños del imperialismo cultural, marginando los valores y las agencias fuera de dicha estructura, encubren al lector, o bien, si es visibilizado, queda significado en un lugar de nimiedad en la significación cultural. De tal modo que, reflexionamos en este artículo sobre las siguientes cuestiones: ¿cuáles son las localizaciones alternas que pueden ser descritas en materia de lectura a través de la diferencia colonial?, ¿cómo cambiar el lugar de enunciación de los lectores y de sus prácticas en el campo de la Educación Inclusiva y la justicia social? una respuesta tentativa a éstas interrogantes reside en la comprensión de los usos ontológicos vinculados a la noción de inclusión, cuya finalidad es ideológico-política-ética. Su "uso en sentido epistemológico de esa noción sirve sólo para reforzar discursos y problemáticas de tipo ontológico y sobre todo para arrojar luz sobre una cierta concepción ético-política respecto de las dinámicas de las identidades culturales"(Mellino, 2008:II5).

\footnotetext{
${ }^{6}$ La multiplicidad constituye el fondo operativo del dispositivo.

7 Según Ocampo (20i8) la Educación Inclusiva es una expresión teórica de la post-crítica, de la multiplicidad de diferencias, de la trasformación y de la transgresión. Bajo ningún punto de vista constituye una práctica específica para un tipo particular de estudiantes, tampoco se concibe como una modalidad alternativa de la educacion, pues implícitamente se atrapa su performatividad en un cambio reduccionista y absoluto, sin efecto en la realidad. Es ante todo, un comentario constructivo que desafía al saber pedagógico contemporáneo.
} 


\section{Una praxis lectora fronteriza}

El ejercicio de los derechos culturales históricamente han sido condicionados por un patrón específico de poder colonial (Quijano, 2000), principal estrategia de regulación de las prácticas lectoras, culturales y educativas. Se convierte así, en un sistema de intermediación en la configuración de las desigualdades estructurales en materia de lectura. Es tarea crítica de la lectura y de sus prácticas liberar a los sujetos a través de prácticas sociales y cultuales concretas. Como tal, consiste en ubicar la reformulación de las prácticas de aseguramiento del derecho a la lectura en la exterioridad (Lazzarato, 2006) y en el pensamiento del afuera (Foucault, I973). Recurriendo a la noción de exterioridad expuesta por James (I9I4), Lévinas (2002) y Lazzarato (2006) es posible reconocer espacios para lograr la emancipación de los lectores y de sus conciencias. Según Dussel (I973, I985 y 2006) las relaciones exteriores constituyen espacios epistémicos no colonizados, no afectados complemtamente por los formatos del poder; espacios que han resistido a la lógica de sentido y a las mascaradas del poder. Una praxis lectora fronteriza estructura su actividad a partir de un sistema de relaciones exteriores en el que convergen y se entrecruzan diversos tipos de proyectos ético-políticos en materia de derecho lector. ¿Cómo funcionan dichos sistemas de relaciones? En palabras de Dussel (I996) las relaciones exteriores otorgan un potencial "instrumental interpretativo suficiente para comenzar un discurso filosófico desde la periferia, desde los oprimidos" (Dussel, 20II:55). Según Ocampo (20I8) el estudio del derecho a la lectura se consagra un campo heterogéneo de prácticas teóricas y metodológicas, lo abierto, denota un sistema de reflexividad flexible que posee la capacidad de conectar en un mismo espacio recursos analíticos epistemológicos, léxicos y metodológicos de diversa naturaleza. Constituye un campo epistemológico de la multiplicidad. Su naturaleza abierta denota la capacidad para ser empleada de diversas maneras; eminentemente moldeable, posibilita el entendimiento de su estructura teórica en términos de pegamento conceptual, es decir, posee la capacidad de conectar elementos de naturaleza heterogéneos -principio de heterogénesisformando una nueva trama teórica y metodológica ${ }^{8}$.

Concebimos el derecho a la educación como una práctica cultural y política diferente e inversa a las formas de universalismo históricamente validadas por el imperialismo cultural convertido en estrategias de configuración de las políticas del libro y las políticas educativas que devienen en una expresión homogeneizadora cerrando sus puertas a los pliegues a la multiplicidad. Es posible afirmar que, los derechos sociales y culturales se articulan desde una perspectiva monológica y monolítica. El pensamiento fronterizo se opone a las prácticas monotópicas que sustentan la actividad de la ciudadanía lectora y cultural, erradicando las relaciones de superioridad frente a otras expresiones y modalidades de intervención cultural y de alfabetización.

\footnotetext{
${ }^{8}$ Principales manifestaciones del principio explicativo de exterioridad de la Educación Inclusiva.
} 
La lectura salva a las personas en la medida en que logra liberarlas de las injusticias distributivas que cooptan su experiencia subjetiva, su propósito no debe reducirse a un conjunto de actos de asimilación y acomodación a lo existente. Emerge así, una operación tropológica orientada a la transformación de la lógica de sentido que sustenta las prácticas de alfabetización dirigidas a legitimar a la multiplicidad de diferencias.

El pensamiento fronterizo consagra un proyecto intelectual y una práctica de investigación de carácter relacional y crítico, rescata diversas figuras de alteridad epistémicas. Así, "el pensamiento fronterizo produce una redefinición/subsunción de las nociones de ciudadanía, democracia, derechos humanos, humanidad, economía y política, más allá de las definiciones estrechas impuestas por la modernidad eurocentrada" (Grosfoguel, 2007: i6). Exterioridad y pensamiento fronterizo subvierte críticamente los esquemas y las visiones totalizantes, sus sistemas categoriales que aprisionan a los sujetos educativos y culturales en modalidades predictivas de su potencia. La relación con el Otro establece un vínculo abierto a lo infinito, libera al sujeto de sí mismo; la exterioridad rompe la relación objetivista que afecta a la comprensión de la naturaleza humana.

Reclamamos en este trabajo la necesidad de concebir al lector y al sujeto educativo como una multiplicidad infinita de diferencias, en las que el sujeto no es presa de ninguna tecnología de sujeción. La parte de ‘multiplicidad' reclama lo heterogéneo, lo diferente, lo plural desde una infinidad de miradas y relaciones; mientras que lo 'infinito' alude al desbordamiento del ser, por esta razón, interrogamos los mapas abstractos del desarrollo -sistemas de sujeción del sujeto en determinadas categorías analíticas-, esta dimensión da cuenta de la vigencia de diversos tiempos, recuperamos en este trabajo la visión del sujeto educativo y del lector como ser de infinitud. Compromete el sentido educativo más allá de su externalidad, es decir, visibilidad que asigna una imagen, que desborda cualquier categoría. Concebir al sujeto como una multiplicidad de diferencia recupera su capacidad de acontecer.

La intersección lectura-ciudadanía consolida un vínculo fronterizo. Para Mignolo (2003) el pensamiento fronterizo surge de la acción subalterna, ensancha la actividad del proyecto modernista eurocéntrico que funda su quehacer educativo y cultural en la universalidad concebida como un todo colectivo, devenido en una estructura de homogenización. Recurrimos a la noción de pensamiento fronterizo con el objeto de deconstruir y reconceptualizar las relaciones ontologizadoras que diferencian al sujeto entre superiores e inferiores, cultos e incultos, letrados e iletrados; se convierte así, en un dispositivo de mediación analítica y epistemológica. También, expresa un carácter deconstruccionista sobre los ejes de sustentación de la filosofía de la cultura popular, reconociendo hasta cierto punto, su carácter esencializador.

Para Eun (20I8) el pensamiento fronterizo se convierte en una estrategia emancipadora cuyo propósito consiste en consolidar una estrategia de pensamiento y de reconocimiento propio de las minorías, concebidas en términos de Guattari y Rolnik (2006) como mayorías en mundo. Forja una comprensión del mundo a partir de las convergencias históricas, políticas, culturales y epistemológicas que sustentan la agencia de la 
subalternidad concebidas como mayorías en el mundo. La justicia emancipadora (Montiel, 20I8) se opone a la aplicación normativa del derecho a la educación y a la lectura, atiende a las articulaciones performativas del poder que forman parte de relaciones intersubjetivas, a través de ella, cristaliza una consciencia revolucionaria, consagra un nuevo estilo de autodeterminación.

¿Qué elementos nos permiten pensar una perspectiva emancipadora postmodernista de tipo oposicional el ejercicio del derecho a la lectura? Una primera aproximación consistiría en disponer de sistemas de razonamientos que trasciendan los mecanismos y estrategias de pensamiento binaristas. En este marco, ¿a qué salidas nos conducen las políticas sobre educación lectora y ciudadanías? La comprensión epistemología de la lectura concebida en tanto práctica social, cultural y política articula una epistemología crítica-compleja, sus tópicos analíticos emergen desde el centro critico de las problemáticas epistémicas del feminismo y de alteridades étnico-racionales (Grosfoguel, 2007). Reconocemos que los estudios de género, los estudios sobre feminismo crítico contemporáneo, la corriente interseccional, los estudios sobre pensamiento decolonial, entre otros, han sido responsable de la apertura y diversificación epistémica y metodológica del estudio de la lectura. La comprensión epistemológica de la lectura se convierte en una visión situada de los problemas sociales y culturales; requiere entonces examinar las condiciones de producción de la lectura y sus mecanismos de arrastre a través de una perspectiva geopolítica del conocimiento recuperando los aportes de Dussel (2OII). Esta es una epistemología que posee emociones, cuerpo, significado y sentido de realidad. Su lugar epistémico de enunciación, devela el lugar -topoi- desde el que hablan de sus sujetos, enuncia las condiciones de injusticia ${ }^{9}$ distributivas -requiere de una concepción de justicia, reconocimiento y redistribución más amplia- y las tecnologías de arrastre a las fronteras del derecho a la educación, develando las coordenadas del poder que sustentan dicha actividad. En esta concepción del cocimiento se rescata la voz del sujeto, nos interesa conectar al lector y ciudadano con las formas de la producción del conocimiento de la lectura y sus modos de interpretación e imaginación de la realidad. Asigna un carácter de paridad en la participación, desinstitucionalizando los marcos de valores hegemónicos de la acción cultural, sustituyéndolos por patrones que la promueven la equidad y la justicia.

Podemos afirmar que la Educación Inclusiva es una expresión post-crítica, fronteriza y de no-lugar. En tanto campo intelectual puede describirse como un terreno fundamentalmente disputado por una multiplicidad indisciplinada de nociones o bien, como un red de relaciones múltiples, en las que sus categorías van y vuelven, operan con circularidad, siendo un campo de complejas rearticulaciones sobre lo diferente o aquello que puede alterar sus formas. La epistemología fronteriza para Mignolo (2003 y 2OII)

\footnotetext{
${ }^{9}$ Coincidiendo con Fraser (2OI2) todos los ejes de injusticia que configuran el funcionamiento del mundo poseen dos dimensiones: la lucha por el reconocimiento y por la redistribución. Ambas son categorías interdependientes. En tal caso, "prácticamente todos entrañan mala distribución y falta de reconocimiento, de modo que ninguna de esas injusticias puede ser corregida completamente de forma indirecta a través de la otra, sino que cada caso requiere" (Fraser, 2OI2: 274).
} 
establece modalidades otras de escolarización, de ejercicio del derecho a la lectura, devela la lógica de funcionamiento de la inclusión, trasforma los contenidos vinculados al estudio de las práctica culturales, etc.

[...] El racismo moderno/colonial, es decir, la lógica de racialización que surgió en el siglo XVI, tiene dos dimensiones (ontológica y epistémica) y un solo propósito: clasificar como inferiores y ajenas al dominio del conocimiento sistemático todas las lenguas que no sean el griego, el latín y las seis lenguas europeas modernas, para mantener así el privilegio enunciativo de las instituciones, los hombres y las categorías de pensamiento del Renacimiento y la Ilustración europeos (Mignolo, 2OII, p.s/a).

Consecuencias de esta naturaleza condicionan la cultura letrada y sus modos de actuación, contrarrestan y superan el corpus de prácticas simbolicas prácticas simbólicas y sutiles de subordinación académica y cultural es el principal propósito de la acción cultural en el marco de la justicia redistributiva. Su aceptación implica históricamente asimilarse y resignarse tal como indica Mignolo (2OII) a la lógica de la exclusión y la devaluación social problema ontológico de los grupos sociales. En este marco, coexisten prácticas de negación de la diferencia y de la multiplicidad, por lo cual, el otro no existe; esta lógica ha imperado a lo largo de la historia intelectual de las prácticas de alfabetización. Tales prácticas ubican a los sujetos en categorías específicas, en este marco los sujetos no existen ontológicamente, únicamente alcanzan un estatus de invención discursiva. Para Mignolo (2OII) se constituye "una unidad que no nombra lo existente, sino que lo inventa" (p.248), requiere de un agente y de una estrategia de gestión del discurso. La dominación constituye una ficción regulativa del otro y de sus posibilidades educativas.

La lectura es un concepto viajero, epistemológicamente, ofrece un itinerario de dispersión y debe ser considerada como un mecanismo de crítica cultural. La lectura en el marco de la Educación Inclusiva deviene en una práctica de desprendimiento y en un pensamiento fronterizo. La formación epistemológica del campo de la lectura social aborda las relaciones de poder, las formas de opresión y su multiplicidad de tecnologías de operación, consolida una estructura teórica abierta y dinámica de entrelazamiento en las que se van engendrando diversos elementos de naturaleza heterogénea. ¿Cómo se práctica este enfoque? En este marco, el campo epistemológico de la lectura social consagra un sistema de prácticas y un quehacer político que opera en la exterioridad.

¿Cómo pensar la lectura en tanto práctica fronteriza?, ¿cómo se lee desde esta frontera? Nos interesa la frontera como un espacio de producción y re-articulación del conocimiento. El pensamiento fronterizo demanda la creación de un andamiaje conceptual, metodológico, epistémico y ontológico para comprender el sentido de la complejidad que sostiene el poder de la acción cultural. La lectura se convierte así en un espacio de intermediación y una espacialidad de demarcación epistémica. Lo fronterizo es sinónimo de una nueva consciencia, como tal, implica nuevas modalidades de historias, de 
relatos, de narrativas, etc., instaura nuevas modalidades de lectura, promueve una lucha hermenéutica, establece nuevas modalidades interpretativas sobre el desarrollo lector y sus formas de aproximación a la lectura.

\section{La negatividad: un principio explicativo de la educación inclusiva}

El principio de negatividad funda su actividad y propósito en el ideal de la transformación social. Caracterizado por un espíritu que todo lo cuestiona o reconceptualiza, inscribe su actividad en la (des)localización. La dialéctica negativa (Hegel, ı969; Benjamin, 2008 y 2009; Matus, 2OI7; Soto, 20I8) se convierte en una herramienta crucial para desmantelar las falsedades articulatorias del sujeto a un determinado objeto. El principio de negatividad es sinónimo de oposición, de crítica, de trasformación y cambio.

Ocampo (20I8) identifica los siguientes principios explicativos que sustentan la actividad de la Educación Inclusiva, ellos son: a) el principio de negatividad, b) el principio de exterioridad, c) el principio de socio-génesis y d) la interseccionalidad epistémica. ¿Cómo se articulan estos principios en la comprensión de las prácticas lectoras centradas en la multiplicidad?, a través de la noción de negatividad, es decir, el espíritu que todo lo cuestiona (Matus, 2OI7) se convierte en una estrategia analítica clave para contrarrestar los efectos del pensamiento de lo idéntico (Adorno, I98I) o el pensamiento de lo mismo (Soto, 2OI8) devenido en un sistema de enmarcamiento del sujeto educativo y de sus fenómenos, en una visión instrumentalizadora de su naturaleza y de las prácticas lectoras y educativas. Esta actividad se sustenta en una visión ontológica de lo mismo, en ella, las prácticas de abordaje de la lectura, adecuan el sujeto al objeto, cristalizando una dimensión unidimensional del proceso formativo. El pensamiento epistemológico de la Educación Inclusiva y la justicia social en su acepción tradicional opera mediante un pensar por lo idéntico, da paso a una posición epistémico-ontológica de tipo modernista de la cultura y de las prácticas letradas. El mecanismo de adecuación del sujeto al objeto niega lo diferente, implica un sistema de adecuación entre subjetividad y objeto. Lo divergente se concibe como lo negativo, lo polifónico, lo diverso, lo múltiple, lo heterogéneo, en suma, la categoría de multiplicidad que estructura la gramática epistemológica de la Educación Inclusiva encuentra su centro crítico de rearticulación en la negatividad. Como tal, se convierte en un sistema de no-adecuación, una estrategia de refutación y reestructuración.

En el lenguaje de la razón técnica, la lectura y sus prácticas culturales, se identifican con la funcionalidad del papel de la lectura como práctica de transmisión de información ${ }^{\mathrm{IO}}$. ¿Cuáles son los conceptos que piensan las prácticas de alfabetización a través de la razón técnica? En esta visión la lectura adquiere un sentido de funcionalización, restringe su capacidad para cuestionar los significados con los que lee e interpreta el mundo. Adecua al lector a una estructura cognitiva institucionalizada.

\footnotetext{
Io Corresponde al principal objetivo de escolarización de la educación lectora.
} 
Las formas lingüísticas que neutralizan la producción de imágenes forjan una práctica de imágenes forja una práctica educativa y un lenguaje anti-histórico, da paso a una comprensión acrítica de la realidad. El lector es objeto de instrumentalización, responde a una práctica de interioridad epistemológica, recurre a conceptos operacionales, "se debe, en primera instancia, a la «unificación de los opuestos» dentro de la trama lingüística. Incluso la casi «desaparición de las contradicciones» en el uso (in) consciente del lenguaje funcional" (Soto, 20I8: 5I). Los conceptos operacionales se vuelven inmunes a la contradicción. Así, "el lenguaje unificado en su estructura semántica es autoinmune a la oposición, a la negatividad. El significado de las cosas reduce el concepto (representación mental) a una o varias funciones identificadas (Soto, 20I8).

La tabla que presentamos a continuación, se propone ilustrar las principales características que adopta una praxis lectora a través del pensamiento idéntico y pensamiento negativo, su contextualización y repercusiones en el contexto de alfabetización de la multiplicidad de diferencias.

\begin{tabular}{|c|c|}
\hline $\begin{array}{l}\text { Pensamiento 'idéntico' de las prácticas } \\
\text { lectoras y de la mediación cultural }\end{array}$ & $\begin{array}{l}\text { Pensamiento 'negativo' de las prácticas } \\
\text { lectoras y de la mediación cultural }\end{array}$ \\
\hline $\begin{array}{l}\text {-Estructura homogénea de justicia social, cul- } \\
\text { tural y educativa. } \\
\text {-La experiencia lectora se vuelve objetivizada. } \\
\text {-Promueve un equívoco de alineación y una vi- } \\
\text { sión de estructura cerrada. } \\
\text {-La diferencia queda sujeta a un sistema de ex- } \\
\text { ternalidad. } \\
\text {-Fomenta un tipo único y homogéneo: crono- } \\
\text { sistema y la experiencia educativa de mono- } \\
\text { cronía. } \\
\text {-Observación neutral del sujeto educativo y de } \\
\text { sus particularidades. } \\
\text {-Su estructura totalitaria sustentada en meca- } \\
\text { nismos de acomodación inscribe la interpre- } \\
\text { tación a un objeto particular. }\end{array}$ & $\begin{array}{l}\text {-Reconoce una praxis social, cultural y educa- } \\
\text { tiva compuesta por una multiplicidad infinita } \\
\text { de diferencias, en ella, lo infinito es concebi- } \\
\text { do como un sistema de ruptura e inadecua- } \\
\text { ción. } \\
\text {-Presencia de un tipo heterocrónico, es decir, } \\
\text { una multitemporalidad. } \\
\text {-La totalidad es concebida en términos de rela- } \\
\text { ciones exteriores, es decir, de singularidades } \\
\text { múltiples. Establece múltiples trayectorias de } \\
\text { relación con el Otro. } \\
\text {-Nada se encuentra reducido a un objeto - } \\
\text { práctica esencialista-, el sujeto se encuentra } \\
\text { en la relación y en la coexistencia. Es un suje- } \\
\text { to de la excedencia, es decir, algo que va más } \\
\text { allá de la totalidad. } \\
\text {-Se estructura sobre los fundamentos de la dia- } \\
\text { léctica negativa, se interesa por identificar la } \\
\text { realidad opresora. Articula su actividad a tra- } \\
\text { vés de un conjunto de relaciones exteriores. } \\
\text {-Se propone crear condiciones de igualación } \\
\text { sobre lo desigual, se inscribe en el plano de } \\
\text { la trascendencia, la responsabilidad y el res- } \\
\text { pecto. Recupera la multiplicidad infinita de } \\
\text { acciones que constituyen la realidad cultural. }\end{array}$ \\
\hline
\end{tabular}


(página anterior) Tabla 1: Principales características del pensamiento idéntico y negativo aplicado al estudio de las condiciones de justicia a través de la Educación Lectora (Fuente: elaboración propia).

\section{La lectura como acontecimiento}

De Mussy y Valderrama (2009) definen el acontecimiento como algo que "no es exactamente lo que ocurre, que es lo que la palabra inglesa sugiere (event), sino algo dado en lo que ocurre, algo que ha sido expresado o realizado, o a lo que se le da forma en lo ocurrido" (p.43). La lectura concebida como acontecimiento no se remite al hecho mismo de leer, sino más bien, algo que actúa en un determinado hecho, es decir, aquello que actúa en la realidad, configura un compromiso ético y político frente a multiplicidad de formas de desigualdades estructurales, adquiere actualidad cuando es capaz de denunciar e identificar las ideologías que sustentan dichas formaciones. Actualidad y presencia de la lectura se expresan mediante la articulación de herramientas que permitan leer críticamente el presente. Al constituir una tarea en permanente movimiento, sus sentidos y modalidades interpretativas se transforman permanentemente. Para Derrida (2000) el carácter de acontecimiento de la lectura además de forjar una herramienta hermenéutica, permite imaginar, es decir, proyectar un mundo otro, al declarar lo que está por venir. La lectura en tanto acontecimiento se encuentra "en íntima relación con las nociones de diferencia, inmanencia y devenir" (Esperón, 2018: 2O7).

Para Bejamin (2009) la lectura como acontecimiento permite observar las lógicas de sentido que sustenta las prácticas culturales en su ejercicio interpretativo de resistencia y protesta cultural, forja un significado fuera-de-la-ley (Žižek, 2OI6). Los hechos se convierten en "una función del significado asignado a los acontecimientos, y no un dato primario que determina qué significado puede tener un acontecimiento" (De Mussy y Valderrama, 2009: 44). El acontecimiento determina los modos en que determinados fenómenos pueden ser significados e interpretados se encuentran en estrecha relación con los hechos que definen su ocurrencia. Son de naturaleza inestable, dinámica y fluida, atienden a los detalles infinitos que participan de cada estructura de desigualdad, concebida como una estructura de extensividad a la experiencia subjetiva de un amplio grupo de ciudadanos. ¿Cómo se expresa el estatus de acontecimiento de la lectura? Si aplicamos dicha pregunta al objeto de análisis de este trabajo, afirmamos que nos interesa demostrar no solo el punto de vista de estructural de las desigualdad, sino más bien, su capacidad acontecimental, es decir, su poder para penetrar en cada una de ellas y subvertir sus modos de funcionamiento. La lectura enfrenta el desafío de develar las formas de acontecer de cada uno de los sistemas de opresión y dominaciones estructurales que restringen el desarrollo oportuno de una amplia multiplicidad de personas y colectivos.

Recuperando la propuesta de Richard (20Oz) nos parece significativo atender a la producción de pseudo-acontecimientos vinculados al estudio de las desigualdades que atraviesan y organizan el campo de lucha del derecho a la lectura. La lectura promulga un 
cambio radical, especialmente, por el agotamiento de las categorías analíticas y mapas cognitivos tradicionalmente empleados. A esto se ha denominado crisis de representación.

La lectura como experiencia reflexiva en la postmodernidad observa que las problemáticas de las prácticas culturales no solo dependen del contenido ideológico de la obra literaria, sino que de la forma en la que emergen sus recursos, tales como, el orden del significante, la gramática, etc. Como soporte cultural la lectura atiende a la creación de modos inéditos de sentido. Es menester liberar las prácticas lectoras de los sistemas de razonamientos heredados de la modernidad, forja nuevas formas de percibir, comprender y ser parte de la acción cultural. De lo contrario, se inserta en categorías que reproducen aquello que criticamos y que hemos heredado de la modernidad. Emergen de la reconfiguración de los modos de subjetivación. Es ante todo creación de lo posible.

¿Es posible comprender lo real del mundo y de sus injusticias a través de la lectura? Una aproximación inicial consistirá en tomar distancia de dicha realidad y de sus formas de marginación para poder observarlas, degustarlas en todo su esplendor, como segundo elemento, observamos relevante examinar los conceptos y las categorías a través de las cuales leemos esa realidad y sus problemáticas, el problema es que estas categorías, no existen, han de ser inventadas, de lo contrario en términos derridanianos, ofrecemos una falsa salida al problema en cuestión. Coincidiendo con Rojas (2OI4) observamos necesario recuperar la voluntad de la lectura desde una historicidad del presente, libera su acción -en permanente movimiento- de la normatividad históricamente legitimada como parte del derecho a la lectura.

\section{Alfabetización crítica y el compromiso ético de la lectura}

Los profesionales de la mediación cultural, de la animación de la lectura y los educadores se convierten en trabajadores culturales. Recuperando el mandato politizador que plantea la Educación Inclusiva y, especialmente, la justicia social en la materia de derecho a la lectura, reconocemos que éste es un campo disputado fundamentalmente por diversos proyectos éticos y políticos. Así, la lectura se convierte fundamentalmente un terreno de disputa política e ideológica, una práctica crítica de la acción cultural. La lectura desde una perspectiva de igualdad y equidad compleja, se convierte en un dispositivo de conexión entre iguales en el espacio público -sistema de paridad descrito por Fraser (2OI2) -, reafirma el ideal de ciudadanía como práctica crítica vinculada al ejercicio de un conjunto de derechos inalienables del ser humano. Las prácticas de lectura que articulan su actividad desde una visión modernista según Benhabib (2008), consolidan la identificad cultural y la legitimidad política a través de la participación ciudadana incrementando los niveles de capacitación, reafirmando una perspectiva instrumental e informacional de la misma, sustentada en un marco normativo y estrecho de la acción democrática y la capacidad transformadora de las prácticas culturales y educativas. El reconocimiento a 
través del derecho a la lectura establece una relación constitutiva de subjetividad. Fraser (2008) insiste agregando que,

[...] el "reconocimiento" implica la tesis hegeliana, considerada a menudo opuesta al individualismo liberal, de que las relaciones sociales son anteriores a los individuos y la intersubjetividad es anterior a la subjetividad. Es más, a diferencia de la redistribución, suele interpretarse que el reconocimiento pertenece a la "ética", en cuanto opuesta a la "moral", es decir, que promueve los fines fundamentales de la autorrealización y la vida buena, frente al "derecho" de la justicia procedimental (p.85).

Una de las tareas críticas que enfrenta la lectura en el contexto de Educación Inclusiva consiste en articular procesos que permitan liberar la memoria (Ricoeur, 2000; Sarlo, 2005; Benjamín, 2008; Seydel, 20I4), con el objeto de abordar "la cuestión de cómo el poder, la historia y la cultura están organizados para afianzar la autoridad y los intereses de grupos especificos"(Giroux, 1997: 266), informando acerca de "lo que se está valorizando es el lenguaje dominante de la industria de la cultura es una visión elitista del desarrollo personas y social basado en la celebración de la homogeneidad cultural, una aproximación antidemocrática a la autoridad social"(Giroux, I997: 266).

$\mathrm{Al}$ asumir la Educación Lectora en tanto compromiso ético, proyecto político y estrategia de lucha en la construcción de justicia, proliferan desafíos tales como:

- Reformulación de conceptos para leer críticamente el presente. Forja una historicidad del presente.

- Sistematiza elementos que permitan construir una práctica emancipadora en materia de lectura.

- Se opone a la práctica normativa y liberal de libertad y equidad conducente al abordaje de derechos homogéneos para los Otros -efecto esencialista, asimilacionista y arbitrario-. Énfasis en el igualitarismo.

- Establece nuevos modos de investigación crítica dirigida a cuestionar las formas de dominación cultural hegemónicas.

- Crea conceptos y vocabularios que permitan interrogar los lugares de producción cultural.

- Atiende críticamente al falso sentido de igualdad en las propuestas de Educación Lectora y al tipo de distorsiones ideológicas que sustentan sus planteamientos, cristalizando modos de alfabetización se alojan en su interior. 
- Analiza los sistemas de legitimación de determinadas culturas al interior de cada escuela y práctica cultural y el tipo de culturas que son validadas o no en él. Interpelación de los principales marcos de valores que erigen el funcionamiento de las prácticas letradas.

- Concibe la lectura como productora de identidades, juega un rol preponderante en la modelación de la gramática social y escolar.

- Se propone identificar las formas de colonialismo ideológico y cognitivo que permean silenciosamente los ámbitos culturales a través de la experiencia lectora.

- La lectura se convierte en un espacio de reduccionismo ideológico cuando las políticas educativas en la materia consolidan un conjunto de textos de la cultura clásica, devaluando los ejes articuladores de la filosofía de la cultura popular. Tal como comentamos anteriormente, sostenemos la necesidad de deconstruir -principio de negatividad - el concepto de cultura dominante y popular. $\mathrm{O}$ bien, cuando se emplean para resarcir las virtudes lingüísticas de la civilización -enfoque de gramática traducción-.

Los dispositivos de politización de la lectura persiguen su liberación de mecanismos de colonización cognitivas devenidas en acciones reductoras del Otro -el diferente-, que inscriben su figura equívocamente en identidades subalternizadas, oprimidas e inferiorizadas. Reconoce el problema ontológico de los grupos sociales descrito por Young (2002), sus articulaciones se proponen recuperar las tradiciones culturales de los grupos oprimidos. Atendiendo a la proliferación de nuevas formas de opresión, menosprecio cultural y racismo diferencial que tienen lugar a través del lenguaje del liberalismo y del pluralismo acrítico, es posible determinar los principios explicativos de la didáctica de la alfabetización y diferencia. ¿Qué implica esto?, esencialmente, a través de la comprensión de las diferencias de nuestros estudiantes, se incorporan formas específicas de conocimiento y se consolida una lectura crítica del mundo produciendo nuevas categorías y significados. Cada lector forja su significado y sus modos de lecturar la realidad a partir de la multiplicidad de formaciones sociales y culturales en las que inscribe su actividad. ¿Cuáles son los límites discursivos que marginan determinadas prácticas culturales?, ¿en qué sentido el espacio alternativo se convierte en una práctica de opresión?

La lectura en tanto compromiso ético y proyecto político se convierte en una estrategia fundamental para la construcción del sujeto político en el marco de la multiplicidad, combate las falsas definiciones y estrategias de emancipación, consagra una práctica de liberación mediante la cual es posible atender críticamente las intenciones e influencias invisibles que ubican al lectura como estrategia de creación de oportunidades, habilitación social y la participación en tanto mecanismos de opresión ideológica. Ello es visible 
en la medida que logra articularse "a la democracia y a la justicia social, a la alteridad y a la política de la diferencia" (Giroux, I997: 269). ¿A qué concepto de pluralismo cultural nos conduce este sistema de encuadramiento?, ¿qué régimen visual establece?, ¿cómo son transformadas las desigualdades estructurales en materia de derecho a la lectura?

El concebir la lectura como parte de una actividad política forja herramientas para una vida democrática más amplia, da cuenta de las formas de enmarcamiento de nuestros discursos y las ideologías que las sustentan. Reafirma un proyecto ético y político heterológico. ¿De qué depende esto? La forma de leer el mundo se encuentra implicada en relaciones de poder (Giroux, 1997). No basta con dar voz, la lectura se convierte en un mecanismo de lucha contra las estructuras de dominación y opresión y una forma de poder cultural. ¿Cómo ensanchar la experiencia educativa a través de estos aportes?, el estudio de las prácticas lectoras desde una perspectiva política, recurre a préstamos de diversa naturaleza provenientes del feminismo, de los estudios interculturales y étnicos, del marxistas, del análisis cultural, de la pedagogía crítica, de la post-colonialidad, de los estudios queer, de la decolonialidad, etc., cada uno de sus aportes son rearticulados y sometidos a traducción, con el objeto de rescatar su especifidad en la construcción de un nuevo marco teórico.

La lectura a través del lente epistemológico de la Educación Inclusiva se convierte en un dispositivo performativo, es decir, posee la capacidad de alterar los modos y los significados históricamente instalados como parte de los procesos de escolarización y alfabetización. La lectura puede transformase en un mecanismo de reproducción de la cultura letrada en la medida que privilegia lenguas y formas de culturales legitimadas a través del prima del imperialismo cultural. La lectura se convierte en una estrategia fundamental para la construcción del sujeto político, esta no se reduce a la adquisición instrumental vinculada a la enseñanza de la lectura. El énfasis del pensamiento idéntico (Adorno, I98I) conduce según Giroux (I997) al aprendizaje de reglas culturales estrechas, únicamente interesadas en la dimensión informacional e instrumental de la práctica lectora. ¿Qué dislocaciones plantea esta visión al ejercicio de la competencia lectora y la compresión lectora? La alfabetización crítica se propone articular formas de interpretar el mundo, sus opresiones y sus sistemas de desventaja, construye un lenguaje orientado a develar los ejes de producción del deseo de la subalternidad. Se convierte un punto de confluencia entre diversos agentes, espacios y formas de interacción culturales.

Constituye un dispositivo de oposición a las falsas salidas de emancipatorias, atiende a las opresiones ideológicas que se colocan en juego en políticas en compensación o equiparación social. En efecto, "la alfabetización es crítica en la medida en que hace problemática la estructura misma y la práctica de reconocer que el significado no está fijo y que estar alfabetizado es comprender un diálogo con otros que hablan desde diferentes historias, ubicaciones y experiencias" (Giroux, I997: 282).

El discurso de la alfabetización se encuentra estrechamente vinculado a relaciones de poder. Se convierte en una acción política por el modo y la forma en que leemos el mundo, forjamos nuestra consciencia, ideales y luchas, al interior de una matriz de relaciones de poder específica. Su dimensión ética se alcanza a través de la subjetividad 
que cada lector construye a partir de su relación con la raza, el género, la etnia, la clase y la sexualidad -expresiones analíticas contenidas en la noción de multiplicidad-. Cada lector asume un compromiso ético con la lectura, a partir de su inscripción en cada una de las variables interseccionales antes mencionadas, se preocupa por comprender el lenguaje de la democracia, de lo múltiple, lo particular, lo heterogéneo. Permite examinar las complejidades de la cultura al interior de complejas en relaciones de poder específicas. Al consolidar un lenguaje de la solidaridad, la lectura define formas particulares de estar en el mundo, atiende al modo en que se forman determinadas categorías y cómo estas, participan en la configuración de estructuras de desigualdades específicas y complejas.

La lectura del mundo se construye en los puntos de captura que resulta del cruce complejo no-lineal de cada uno de estos elementos. El compromiso ético de la lectura es clave en la articulación de un discurso de naturaleza de contra-poder, oposicional, antiopresivo y crítico de la realidad. Se convierte en una huella de alteridad en potencia, en una modalidad ética de relación con el otro. El lenguaje de la diferencia se abre al encuentro de los Otros, se propone hacer inteligibles las condiciones de la alteridad. " $\mathrm{La}$ alfabetización significa hacer presente el yo de uno como parte de un proyecto moral y político que vincula la producción del significado con la posibilidad de la acción humana, comunidad democrática y acción transformativa" (Giroux, I997: 283).

En la intersección entre la escolarización, la vida política, las prácticas éticas y lectura, ésta última, juega un papel estratégico en la producción de identidades y modos subversivos de abordaje de la realidad. Interroga, cuestiona y transforma la realidad, la lectura reafirma un compromiso político, ético y moral con la ampliación de los márgenes de la ciudadanía y la condición democrática, agudiza la comprensión de las desigualdades estructurales que permean y afectan la tarea educativa. La lectura como praxis cultural y política amalgama un conjunto de filosofías que se entrelazan y engendran entre sí al interior de una estructura de totalidad dinámica. La lectura en tanto práctica social y política enfrenta el desafío de analizar su lenguaje y su terminología discursiva. Su centro crítico no se reduce a explicar términos, sino más bien a comprender las configuraciones de un nuevo lenguaje como herramientas de análisis estructural de las desigualdades culturales. La lectura como discurso de resistencia concibe la praxis lectora como un lugar político, enfrenta problemáticas ligadas a formaciones culturales específicas. El derecho a la lectura se convierte en una forma política cultural si es capaz de conectarse con las formas particulares de vida de sus usuarios, interroga las modalidades en las que determinados colectivos de sujetos son atrapados y representados en determinadas ideologías, atiende a los modos en los que los estudiantes construyen sus significados y a las categorías que recurren para articular dicho propósito. El derecho a la lectura desde una perspectiva relacional deviene en una teoría de la acción.

Si la lectura se convierte en un tipo de crítica social particular, entonces, es menester fortalecer un vocabulario que otorgue a los trabajadores culturales, mediadores de la lectura y educadores vivenciar el sentido de justicia social, lectura e inclusión más allá de condiciones asimilacionistas y arbitrarias, tal como hemos expuesto y examinado a lo largo del presente trabajo. 


\section{Conclusiones: trastornar el tiempo pedagógico y cultural}

El estudio de la lectura desde la perspectiva que proponemos en este trabajo, demanda formas otras de relación con el tiempo, ¿cómo abordar las complejidades del tiempo en los procesos de educación lectora?, ¿es posible superar las inflexibilidades temporales que atraviesan las prácticas culturales y educativas históricamente legitimadas por los procesos de escolarización?

Históricamente, la noción de tiempo en las prácticas educativas ha sido sometida a la tiranía de un tiempo universal denominado cronosistema-monocronía-, un tiempo único, homogéneo, sistemático y continuo en el que la totalidad de estudiantes -concebidos en bloques- hacen lo mismo. Ejemplo de cronosistema aplicado a los procesos de Educación Lectora lo constituyen las prácticas de lectura silenciosa sostenida cada mañana al inicio de cada nueva jornada, o bien, las lecturas de libros y otros materiales instruccionales en plazo establecido de forma imparcial para todos los lectores. La homogenización temporal se expresa mediante una actividad formativa restrictiva de la multiplicidad, es decir, articula su actividad en un tiempo y en un desempeño único.

Atendiendo a la propuesta conceptual que efectuamos desde el Centro de Estudios Latinoamericanos de Educación Inclusiva (CELEI) respecto de la noción de multiplicidad de diferencias, observamos incompatibilidad del tiempo único, recurriendo al principio explicativo de exterioridad de la inclusión; lo oportuno, entonces, es reconocer la multiplicidad de temporalidades que se entrecruzan y tienen lugar al interior del espacio escolar. Hablamos así, de hetrocronías de aprendizaje (Ocampo, 20I8). El sujeto educativo y cultural articula un tiempo único de aprendizaje y, específicamente, de lectura. Al observar esto, nos enfrentamos al reconocimiento de un cruce de temporalidades, un tiempo pedagógico multitemporal, permitiéndonos afirmar que, la praxis lectora es una praxis de la heterocronía. La heterocronía atiende a la singularidad lectora, lo que no debe confundirse con los mecanismos de divisibilidad del tiempo. Según Bal (2018) mediante la noción de heterocronía "nos encontramos multi-temporalizados: viviendo simultáneamente, ritmos diferentes en un mismo tramo de tiempo"(p.IO).

La multiplicidad de diferencias se sustenta en el reconocimiento del cruce de diversas experiencias-temporalidades que configuran la práctica escolar. La desatención a estas especificidades configura formas de opresión, la negación del tiempo singular de aprendizaje de cada persona y la insistencia por promover un marco de acción homogénea, constituyen aspectos claves para la justificación esencialista y opresiva de la inclusión.

De modo que, la heterocronía se convierte en un aspecto clave en la comprensión de las imágenes que las personas fabrican a partir de lo que leen, incide y condiciona en la acción cultural. Heterocronía es sinónimo de un tiempo pedagógico múltiple. Si la naturaleza ideológica y discursiva de la Educación Inclusiva reafirma un sentido performativo, entonces, la noción de temporalidad también adquiere dicha escenificación. Posee la capacidad de alterar los modos de escolarización y alfabetización. Contrariamente, el 
tiempo pedagógico es objeto de sujeción a la tiranía de una singularidad absoluta. La trama heterocrónica determina una nueva política del tiempo educativo, en la que la "heterogeneidad del espacio es comparable a la heterocronía" (Bal, 2018: I7). 


\section{Referencias bibliográficas}

-Adorno, T. (198I). Tres estudios sobre Hegel. Madrid: Taurus.

-Anzaldúa, G. (1987). Bordelands/La Frontera: the new mestriza. San Francisco: Aunt Lute.

- Bal, M. (20I8). El tiempo que se toma, Contra Narrativas, Núm. o, pp.8-2I.

- Benhabib, S. (2008). Otro universalismo: sobre la unidad y diversidad de los derechos humanos, ISEGORÍA. Revista de Filosofía Moral y Política, 39, I75-203.

- Benjamin, W. (2008). Obras completas. Tomo II. Madrid: Editorial Herder.

- Benjamin, W. (2009). Para una crítica de la violencia. México: Fondo Cultura Económica.

- De Mussy, L., Valderrama, M. (2009). Historiografía postmoderna: conceptos, figuras y manifiestos. Santiago: RIL/Universidad Finnis Terrae.

- Derrida. J. (2000). Dar la muerte. Barcelona: Paidós.

- Dussel, E. (1973). América Latina dependencia y liberación. Buenos Aires: Edi. Fernando García Cambeiro.

- Dussel, E. (1985). La exterioridad en el pensamiento de Marx, en: Aguirre, J.M. (Comp.). Pensamiento Crítico, ética y absoluto. México: Edit. Eset.

- Dussel, E. (2006). De la fenomenología a la liberación. Recuperado el día I3 de enero de 2OI9 de: http://bibliotecavirtual.clacso.org.ar/clacso/otros/2OI2O227O25302/3cap2.pdf

- Dussel, E. (20II). Filosofía de la liberación. México: Fondo de Cultura Económica.

- Esperón, J. P. (20I8). Acontecimiento, diferencia y abismo. Diálogo crítico entre Heidegger y Deleuze, Anales del Seminario de Historia de la Filosofía, págs. 459-483.

- Eun, J. (2018). Pensamiento fronterizo, en: Diccionario del Pensamiento Alternativo II. Edición en línea. Consultado el o9.or.2Org: http://www.cecies.org/articulo.asp?id= 569

- Foucault, M. (г973). La verdad y las formas jurídicas. Barcelona: Gedisa.

- Fraser, N. (2008). La justicia social en la era de la política de identidad: redistribución, reconocimiento y participación. Revista de trabajo, 4(6).

- Fraser, N. (2OI2). La política feminista en la era del reconocimiento: un enfoque bidimensional de la justicia de género, ARENAL, ı9:2; julio-diciembre 20I2, 267-286. 
- Giroux, H. (1997). Cruzando límites. Trabajadores culturales y políticas educativas. Buenos Aires: Paidós.

- Grosfoguel, R. (2007). Implicaciones de las alteridades epistémicas en la redefinición del capitalismo global: transmodernidad, pensamiento fronterizo y colonialidad global. Uno solo o varios mundos? Diferencia, subjetividad y conocimientos en las ciencias sociales contemporáneas, 99-II6.

- Guattari, F., Rolnik, S. (2006). Micropolítica. Cartografías del deseo. Madrid: Traficante de Sueños.

• Hegel, G.W.F.(I969). Fenomenología del espíritu. Mexico: Edit. Siglo XXI Editores.

- James, (1914). Introduction à la philosophie. París: Marcel Rivière

- Lazzarato, M. (2006). Por una política menor. Acontecimiento y política en las sociedades de control. Madrid: Traficante de Sueños.

- Lévinas, E. (2002). Totalidad e Infinito: ensayo sobre la exterioridad. Salamanca: Sígueme.

- Marcuse, H. (1998). El hombre unidimensional. Barcelona: Editorial Tecnos.

- Matus, T. (20I7). Punto de Fuga. Imágenes dialécticas de la crítica en el Trabajo Social Contemporáneo. Buenos Aires: Editorial Espacio.

- Mezzadra, S. (2008). La condición postcolonial. Unas notas sobre la cualidad del tiempo, en: Mezzadra, S., Spivak, G., Talpade, Ch., Mohanty, Shohat, E., Hall, S., Chakrabarty, D., Mbembe, A., Young, R., Puwar, N., Rahola, F. Estudios Postcoloniales. Ensayos fundamentales (26I-278). Madrid: Traficante de Sueños.

- Mignolo, W. (20II). "Geopolítica de la sensibilidad y del conocimiento. Sobre (de) colonialidad, pensamiento fronterizo y desobediencia epistémica", Revista de filosofía, $74(2)$.

- Mignolo, W. D. (2003). Historias locales/diseños globales: colonialidad, conocimientos subalternos y pensamiento fronterizo (Vol. I8). Madrid: Ediciones Akal.

- Mellino, M. (2008). La crítica postcolonial. Madrid: Traficante de Sueños.

- Mohanty, Ch. (2008). Bajo los ojos de occidente, en: Mezzadra, S., Spivak, G., Talpade, Ch., Mohanty, Shohat, E., Hall, S., Chakrabarty, D., Mbembe, A., Young, R., Puwar, N., Rahola, F. Estudios Postcoloniales. Ensayos fundamentales (69-IO2). Madrid: Traficante de Sueños. 
- Montiel, Z. (2018). Justicia Emancipadora, Diccionario del Pensamiento Alternativo II. Edición en línea. Consultado el o9.OI.2OI9: http://www.cecies.org/articulo.asp?id= ${ }^{5}{ }^{2}$

- Ocampo, A. (2018). Sobre la condición tropológica de la Educación Inclusiva: elementos para una nueva crítica educativa, Polyphonia. Revista de Educación Inclusiva, Vol. 2, num.2, págs. I6-46. Consultado el I 4 de enero de 20I9: http://revista.celei.cl/index.php/PREI/ article/view/ı6-46

- Quijano, A. (200o). Colonialidad del poder, eurocentrismo y América Latina, Recuperado el o7 de enero, 20I9 de: http://www.decolonialtranslation.com/espanol/quijano-colonialidad-del-poder.pdf

- Richard, N. (2007). Fracturas de la memoria: arte y pensamiento crítico. Buenos Aires: Siglo XXI Editores.

- Ricoeur, P. (200o). La memoria, La historia, el olvido. Trad. Agustín Neira. México: Fondo de Cultura Económica.

- Rojas, S. (20I4). Entrevista. Recuperado el día i2 de enero de 2019 de: http://www.artes.uchile.cl/noticias/I42638/sergio-rojas-hoy-la-transgresion-en-el-arte-es-golosina-demercado

- Sarlo, B. (2005). Tiempo pasado. Cultura de la memoria y giro subjetivo. Una discusión. México: Editores Siglo XXI.

- Seydel, U. (20I4). La constitución de la memoria cultural. Recuperado el I3 de enero de 2OI9 de: http://www.scielo.org.mx/pdf/ap/v35n2/v35n2aI2.pdf

-Shohat, E. (2008). Notas sobre lo «postcolonial», en: Mezzadra, S., Spivak, G., Talpade, Ch., Mohanty, Shohat, E., Hall, S., Chakrabarty, D., Mbembe, A., Young, R., Puwar, N., Rahola, F. Estudios Postcoloniales. Ensayos fundamentales (IO3-I2O). Madrid: Traficante de Sueños.

- Soto, J. C. (20I8). Pensamiento de la Identidad, lenguaje unidimensional y dialéctica negativa. Una reflexión educativa desde H. Marcuse y Th. W. Adorno, Teoría Educativa, 3o, 2-20I8, 43-72.

- Spivak, G. (2008). "Estudios de la Subalternidad. Deconstruyendo la historiografía", en: Mezzadra, S., Spivak, G., Talpade, Ch., Mohanty, Shohat, E., Hall, S., Chakrabarty, D., Mbembe, A., Young, R., Puwar, N., Rahola, F. Estudios Postcoloniales. Ensayos fundamentales (33-68). Madrid: Traficante de Sueños.

- Young, I.M. (2002). Justicia y Política de la Diferencia. Valencia: Cátedra.

- Zizek, S. (20I6). La permanencia en lo negativo. Buenos Aires: Ediciones Godot. 